\title{
The Impact of Intensive Care Change of System on Patients Outcome: Open versus Semi Close Intensive Care System
}

\author{
Rabiu MB, Ibrahim SA, Suleiman ZA
}

\section{Abstract - Purpose of the study /Objective}

The purpose of this study is to audit impact of Anesthesiologist on patient outcomes, the objective of this study is to evaluate the impact of change in system of ICU patient's care on outcome.

\section{Background}

Abubakar Tafawa Balewa University Teaching Hospital since its establishment in $\mathbf{2 0 1 0}$ operate two bed Intensive Care Unit (ICU). In 2017 following employment of consultant Anesthesiologist, the ICU care system was changed from open to semi-close Intensive Care System

Methods

Medical records of all consecutive patients admitted to the ICU from May 2016 to April 2017 (open system $n=76$ ) and from May 2017 to April 2018 (Semi-close system $n=92)$ were reviewed. The variables studied were Mortality, ICU length of stay and incidence of acute kidney injury.

\section{Results}

Mortality was $56.6 \%$ in the open system group and $\mathbf{2 9 . 3 \%}$ among the patients in the semi-close system group $(p=0.001)$. The length of ICU stay was $5.4 \pm 5$ and $4.5 \pm 4$ days for open system and semi-close system groups respectively, while the incidence of acute kidney injury among the open system group was $44.7 \%$ and $12 \%$ among the patients in the semi-open system $\operatorname{group}(\mathbf{p}=\mathbf{0 . 0 0 1})$.

Conclusion

Results from this study revealed that, semi-close system care of critically ill patients is associated with lower mortality.

Index Terms - Intensive care, system, outcomes.

\section{INTRODUCTION}

An intensive care unit (ICU) is a designated ward of a hospital which is specially staffed and equipped to provide observation, care and treatment to patients with actual or potential life-threatening illnesses, injuries or complications, from which recovery is possible. ${ }^{1,2}$ Intensive care unit comprise approximately $10 \%$ of acute care hospital beds ${ }^{2}$ Proper organization of medical and nursing care such as communication and collaboration with other stake holders is paramount in improving the quality of ICU outcome, organizational features relating to medical and nursingleadership, communication and collaboration among providers, and approaches to problemsolvingmay capture the quality of ICU care more comprehensively than do practices related to specific processes of care.Most features of ICU organization do not exert a demonstrable impact on clinical outcomes such as morbidity and mortality. ${ }^{3}$ While hard clinical outcomes may not represent the most appropriate measure of success for many organizational features, the role of "intensivists"(specialists in critical care medicine) in managing ICU patients has shown a beneficial impact on patient outcomes in a number of studies ${ }^{1-4}$

Clinical outcome is one of the important parameters to measure success in health system. In Africa and Sub - Sahara there are few trained intensivists, therefore anesthesiologist by virtue of their training take leadership in management of critically ill patients in ICU.System of patient care in the intensive care could be open, semi-close and close system-Open ICU care system. In open system the primary physician of the patient admit and managed the patient whilein semi-close system primary physician send a consult to Anesthesiologist or an intensivist whom admit the patient and lead the care

\section{MATERIAL AND METHODS}

This study is a retrospective study of all consecutive patients admitted at the ICU of Abubakar Tafawa Balewa University Teaching Hospital. ICU from May 2016 to April 2018. Abubakar Tafawa Balewa University Teaching Hospital in May 2017 change the hospital intensive care system of patient management from open system to semi-close system. During the open System of care, from May 2016- April 2017 April $2018(\mathrm{n}=76)$ patients were admitted and managed by their primary physician, while during the semi-close from May 2017 to April 2018( $\mathrm{n}=92)$ primary physician co-managed patients with Anaesthesiologist whom lead the patient care. Medical records of all patients were reviewed, the reviewer had no prior knowledge on study objective and the reason for different study periods that were chosen. The reviewer was not involved in the medical care the patients under review. The variables studied were Age, sex, occupation, ICU length of stay, incidence of acute kidney injury,Serum Creatinine within first 24 hours of ICU admission was used as Reference creatinine. GFR was calculated based on modification for diet renal source of admission, Outcome was categorized as survived for those patients transfer out of the unit and Died for patients that died from any cause during ICU admission.Length of ICU Stay was define as duration of ICU admission in days. 
III. RESUltS

Table 1: Demographics

\begin{tabular}{|c|c|c|}
\hline VARIABLES & $\begin{array}{l}\text { Open- system } \\
\mathrm{n}=76\end{array}$ & $\begin{array}{r}\text { Semi }- \text { close } \\
n=92\end{array}$ \\
\hline Ageyears ( $\pm \mathrm{SD})$ & $34.5 \pm 18$ & $32.0 \pm 20$ \\
\hline \multicolumn{3}{|l|}{ Sex } \\
\hline Male & $36(47.4 \%)$ & $30(32.6 \%)$ \\
\hline Female & $40(52.6 \%)$ & $62(67.4 \%)$ \\
\hline \multicolumn{3}{|l|}{ Occupation } \\
\hline Non-Labour & $59(77.6 \%)$ & $71(77.2 \%)$ \\
\hline Civil Servant & $5(6.6 \%)$ & $8(8.7 \%)$ \\
\hline Self Employed & $12(15.8 \%)$ & $13(14.1 \%)$ \\
\hline
\end{tabular}

The mean age standard deviation was $34.5 \pm 18$ for the open system group and $32 \pm 20$ for the semi-close system patientsMajority $(67.4 \%)$ of the patients in semi-close system were females, non-labour force were the majority $77.6 \%$ and $77.2 \%$ among the open and semi-close respectively shown in table 1 .

Table 2: Clinical Variables

\begin{tabular}{lll}
\hline Variables & $\begin{array}{l}\text { Open-System } \\
\mathrm{n}=76\end{array}$ & $\begin{array}{l}\text { Semi-close system } \\
\mathrm{n}=92\end{array}$ \\
\hline & & \\
Length of ICU Stay (days) & $4.5 \pm 4.2$ & $5.09 \pm 5.4$ \\
Incidence of AKI & $34(44.7 \%)$ & $11(12 \%)$ \\
Mechanical Ventilation & $3(3.9 \%)$ & $57(62 \%)$ \\
\hline
\end{tabular}

Table 2 showed ICU length of stay was longer during the semi-close system of care $(4.5 \pm 4.2$ versus $5.1 \pm 5.4)$ days. Patients among Open system were found to have significantly high incidence of acute kidney injury $44.7 \%$ compared to $12 \%$ among the semi-open system patients.Majority $62 \%$ of patients were ventilated during the semi-close system .

\begin{tabular}{llr} 
& \multicolumn{2}{c}{ Table 3: Outcome } \\
\hline Variables & $\begin{array}{l}\text { Open-system } \\
\mathrm{n}=76\end{array}$ & $\begin{array}{c}\text { Semi }- \text { close } \\
\mathrm{n}=92\end{array}$ \\
\hline Outcome & & $65(70.7 \%)$ \\
Survived & $33(43.4 \%)$. & $27(29.3 \%)$ \\
Died & $43(56.6 \%)$ & \\
\hline
\end{tabular}

Table 3: Showed mortality was significantly lower among the patients managed during semi-open system $29.3 \%$ compared to open $56.6 \%$ system $(p=0.01)$

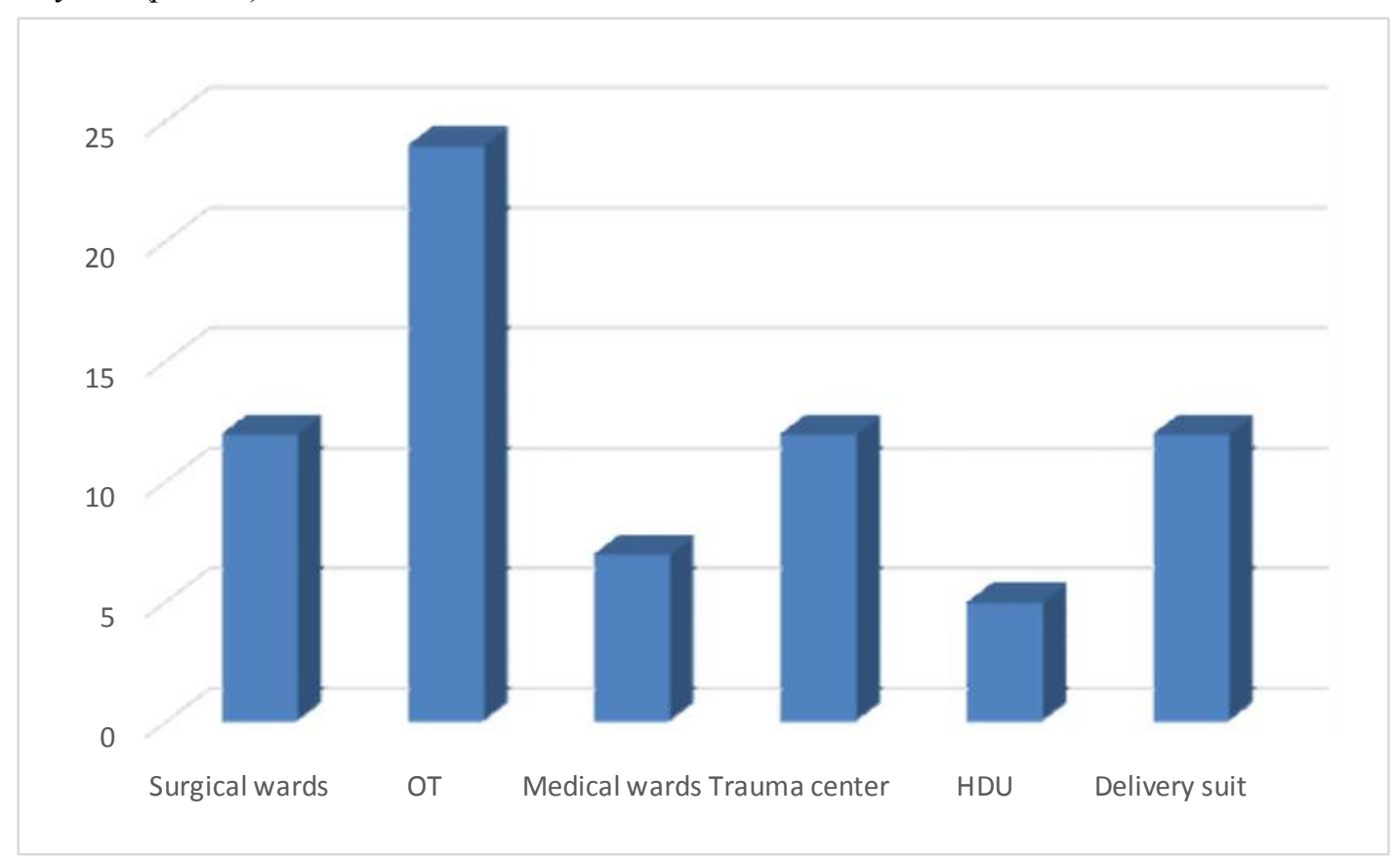

Figure 1: Source of admission during the open system 


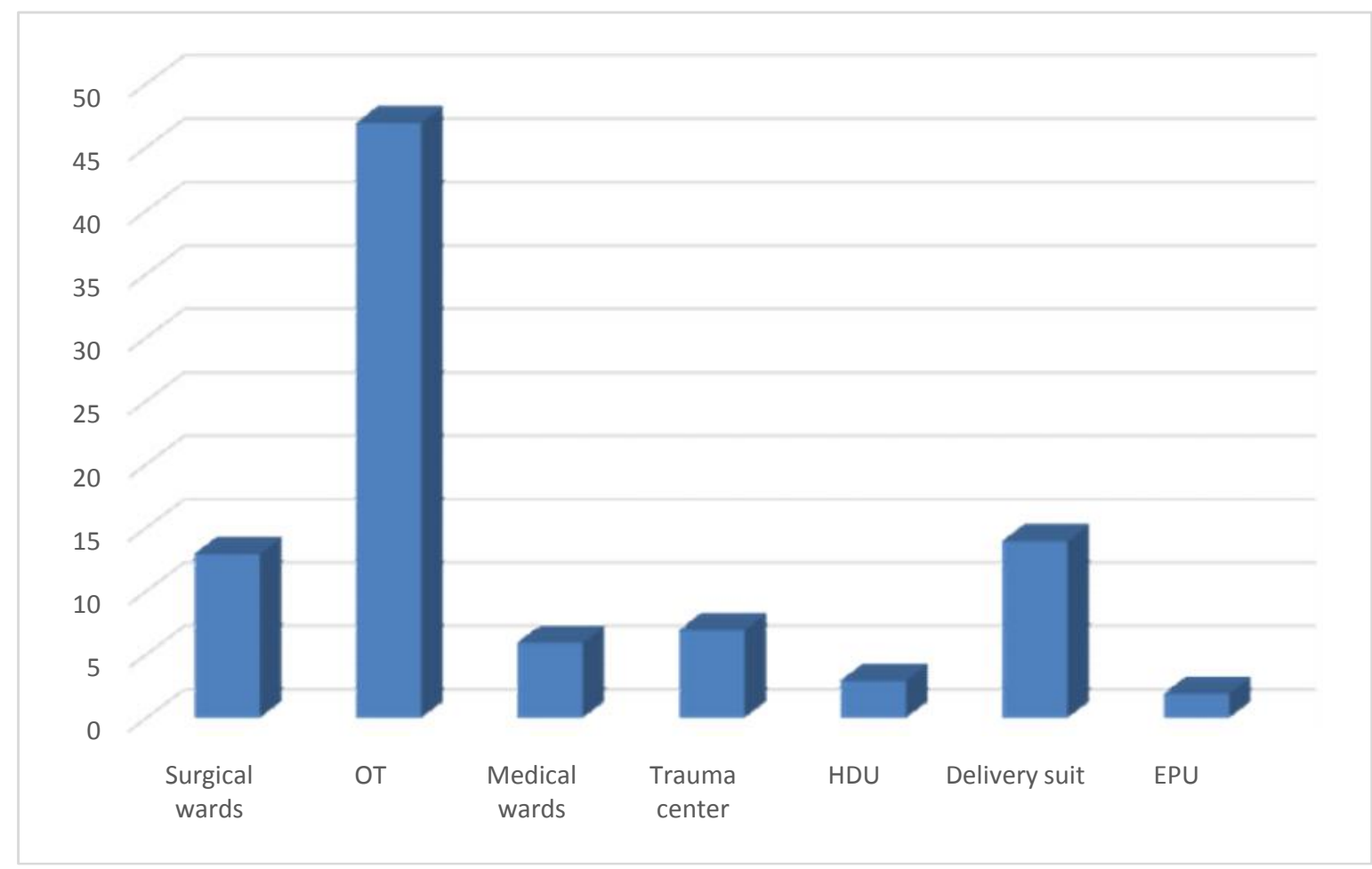

Figure 2: Source of admission during the semi-close system

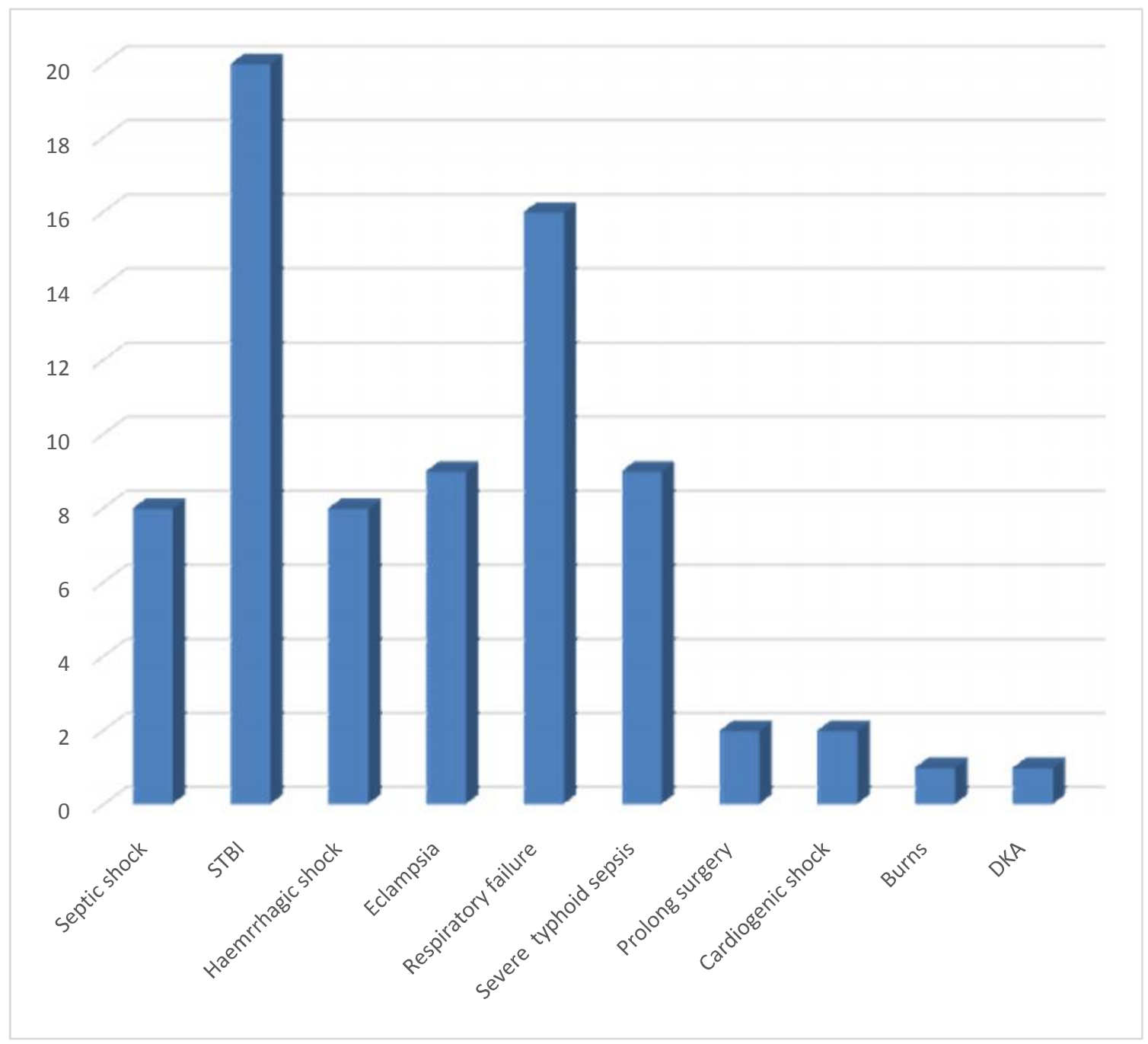

Figure 3: Indication for admission during open system 


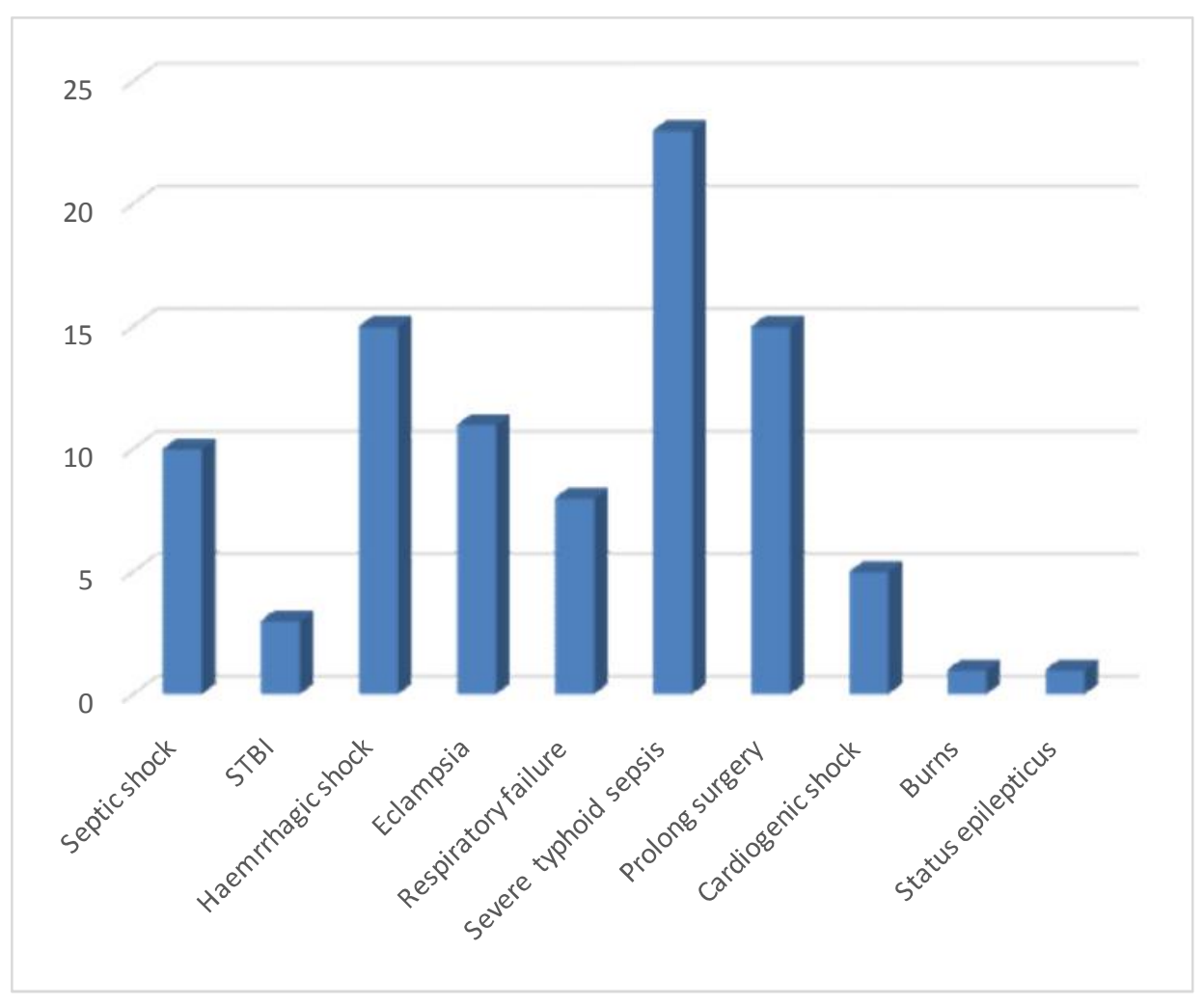

Figure 4: Indication for admission during semi-close system

\section{DISCUSSION}

This study showed, physicians without training in critical care medicine tend to have higher admittance threshold, ninety two patients were admitted during an Anaesthesiologist lead care (semi-close system) compared to seventy six patients during the open system, indicating more patients were admitted during semi-close system compared to open-system of ICU care. Although during the open system,before system change patients were admitted into the ICU by any one of the patient's primary physicians and admission is also subject to intensive care nurses review this may affect the objectivity of the admission policy, During the semi-close system patient admission were decided only by the consultant Anesthesiologist. Our study revealed changing system of ICU system of care from open to semi-closed system is associated with about $27.3 \%$ reduction of mortality among the ICU patients. Twice a day ward round was introduceby an Anesthesiologist during the semi-close system, this might resulted in an improved care of the patient, because it allow for earlier diagnosis and prompt treatment of specific set of complications, this might be the reason for significant decrease in mortality and morbidity observed among the semi-close patient group.

The incidence of acute kidney injury was significantly reduced among the patients in semi-close system compared to those in open system. Our study showed that, patient duration of ICU stay was longer during semi-close system compared to the open system, this may be due to the facts that during the semi-close system patients were transferred out of the unit based on discharge criteria as per unit protocol under supervision of an Anesthesiologist. While during the open system patients are transfer at discretion of the primary physician whom without critical care training and there was no discharge protocol. Only few patients were mechanically ventilated during the open system despite the number of patients admitted with severe traumatic brain injury and respiratory failure during the open system were higher compared to semi-close system. This may explain the higher mortality among the patients in open system, although baseline severity assessment of diseases among the patients was not included in this study which may implies the increase risk of death among a particular study group.

Intensive care unit patients have, an average mortality rates between 12 and 17\%. ${ }^{1,2}$ Overall, a recent review estimated that this mortality could be reduced by 15 to $60 \%$ using an Intensivist model of ICUmanagement. ${ }^{1}$ Young et $\mathrm{al}^{2}$ have provided estimates of the relative reduction in annual Intensive Care Unit mortalities resulting from conversion of all urban ICUs to a physician with intensive care training model of management. Using conservative estimates for current ICU mortality rates of $12 \%$, and estimatingthat $85 \%$ of urban ICUs are not currently Intensivist-managed, the authors calculated that approximately 360,000 patients die annually in urban ICUs without Intensivists. ${ }^{3}$ Similarly using same estimation, projection of a $15 \%$ relative reduction in mortality resulting from physician with training iintensive care training managed critical Care Units yields a predicted annual saving of nearly 54,000 lives, in comparison with this study majority of the studies were done under the Intensivist model. ${ }^{4}$ but most of the studies were done in developed countries where the resources both human and equipment are readily available compared to Low and Middle Income 
Countries which face inadequately prepared health systems with inadequate human resources and lack of basic equipment to address the problems associated with critical care system and health care delivery in general. Considering the resources needed for management of critical care patients, in most developing countries where this resources are limited, anaesthetists are the primary managers of ICU as in the West African sub- region due to lack of Intensivists. This analysis may not underestimate the importance of anesthesiologist-managing intensive care units (ICU),In addition to mortality because significant improvement in outcome similar to the obtained during intensivist model is attainable as recorded in this study, other quality of care outcome measures that might be improved by an anesthesiologists include rates of ICU complications and inappropriate Intensive Care Units utilization.In our study we found that, mortality decreased significantly after format change, this finding is in accordance with the results of similar observational studies performed in various populations. ${ }^{1-5}$

Most studieson ICU format change and physician staffing patterns observe a decrease in total andIntensive Care Unit(ICU) length of stay (LOS). ${ }^{1,6}$ In contrast to this studies we observed an increase in total ICU admission and ICU length of stay. Also improved treatment of severe complications may have resulted in an improved survival at the cost of a longer ICU stay, although the current study does not provide evidence of cost effectiveness in relation to length of ICU stay and none of those studies included a similar comparison for an anesthesiologist in semi- open in both time periods. The other major limitation associated with comparing mortality rates for ICU patients relates to differences in ICU admission and discharge criteria for different illness and under different organizational models.

\section{CONCLUSIONS}

Measuring outcomes in critical care is particularly challenging for several reasons. It relies on observational outcomes studies, and must account for the diversity and complexity of variables measured due the nature of the patient condition, however this study fairly and clearly shows that an anesthesiologist lead care favorably impact improved ICU patientoutcomes. Anesthesiologist by virtue of their training can provide leadership in management of critically ill patients in ICU with significant improvement of outcomes especially in limited resource setting were trained intensivists are not readily available.

\section{REFERENCES}

[1] Rubins H, Moskowitz M. Complications of Care in a Medical Intensive Care Unit. J Gen Intern Med. 1990;5:104-109.

[2] Groeger JS, Guntupalli KK, Strosberg M, Halpern N, Raphaely RC, Cerra F, et al.Descriptive analysis of critical care units in the United States: patient characteristics andintensive care unit utilization. Crit Care Med. 1993;21:279-291

[3] Young M, Birkmeyer J. Potential reduction in mortality rates using an intensivist model to manage intensive care units. Eff Clin Pract. 2000;3:284-289.

[4] Ferraris VA, Propp ME. Outcome in critical care patients: a multivariate study. Crit Care Med.1992;20:967-976.

[5] Angus DC, MB C, Kelley MA, MD, Schmitz RJ et al. Current and projected workforce requirements for care of the critically ill and patients with pulmonary disease: can we meet the requirements of an aging population? JAMA. 2000;284:2762-7270.

[6] Pronovost PJ, Young T, Dorman T, Robinson K, Angus D. Association between ICU physician staffing and outcomes: A systematic review. Crit.Care Med. 1999;27:A43. Abstract

[7] Knaus WA, Wagner DP, Zimmerman JE, Draper EA. Variations in mortality and length of stay in intensive care units. Ann Intern Med. 1993;118:753-761.

[8] Zimmerman JE, Shortell SM, Rousseau DM, Duffy J, Gillies RR, Knaus WA, et al. Improving intensive care: observations based on organizational case studies in nine intensive care units: a prospective, multicenter study. Crit Care Med. 1993;21:1443-1451. 